\title{
Estratégias de integração das práticas assistenciais de saúde e de vigilância sanitária no contexto de implementação da Rede Cegonha
}

\author{
Strategies for integration of health care practices and sanitary \\ surveillance in the context of the implementation of Rede Cegonha \\ - a Brazilian mother and infant health care network
}

Roberta Zanelli Sartori Fernandes ${ }^{1}$

Maria Filomena de Gouveia Vilela ${ }^{1}$

${ }^{1}$ Departamento de Saúde Coletiva, Faculdade de Ciências Médicas, Universidade Estadual de Campinas. R. Tessália Vieira de Camargo 126, Unicamp. 13083-887 Campinas SP Brasil.

robertinhazs@hotmail.com

\begin{abstract}
Mother and infant mortality has been the scope of analysis throughout the history of public health in Brazil and various strategies to tackle the issue have been proposed to date. The Ministry of Health has been working on this and the Rede Cegonha strategy is the most recent policy in this context. Given the principle of comprehensive health care and the structure of the Unified Health System in care networks, it is necessary to ensure the integration of health care practices, among which are the sanitary surveillance actions (SSA). Considering that the integration of health care practices and SSA can contribute to reduce mother and infant mortality rates, this article is a result of qualitative research that analyzed the integration of these actions in four cities in the State of São Paulo/Brazil: Campinas, Indaiatuba, Jaguariuna and Santa Bárbara D'Oeste. The research was conducted through interviews with SSA and maternal health managers, and the data were evaluated using thematic analysis. The results converge with other studies, identifying the isolation of health care practices and SSA. The insertion of SSA in collectively-managed areas appears to be a potential strategy for health planning and implementation of actions in the context under scrutiny.
\end{abstract}

Key words Comprehensive health care, Sanitary surveillance, Mother and child health, Health management
Resumo As mortalidades maternas e infantis têm sido objeto de análise ao longo da história da saúde coletiva no Brasil e diversas têm sido as estratégias de enfrentamento propostas. O Ministério da Saúde tem trabalhado nesse sentido, sendo a estratégia da Rede Cegonha a mais recente politica nesse contexto. Tendo em vista o princípio da integralidade e a conformação do Sistema Único de Saúde (SUS) em redes de atenção, faz-se necessária efetiva integração das práticas em saúde desenvolvidas, dentre as quais estão as ações de Vigilância Sanitária (Visa). Considerando que a integração de práticas assistenciais e de Visa pode contribuir para melhorias nas taxas de mortalidade citadas, este artigo é decorrente de uma pesquisa qualitativa que analisou a integração destas ações em quatro municípios do Estado de São Paulo: Campinas, Indaiatuba, Jaguariúna e Santa Bárbara D'Oeste. A pesquisa foi realizada através de entrevistas com gestores de Visa e de saúde da mulher, e os dados foram analisados através da técnica de análise temática. Os resultados convergem com outros estudos, identificando o isolamento das práticas assistenciais e de Visa. A inserção da Visa nos espaços coletivos de gestão mostra-se estratégia em potencial para o planejamento e execução das ações de saúde no contexto estudado.

Palavras-chave Integralidade, Vigilância sanitária, Saúde materno-infantil, Gestão em saúde 


\section{Introdução}

As últimas décadas do século XX e início do século XXI foram marcadas por grandes avanços nos campos científico e tecnológico, o que tem sido apontado como determinante para múltiplas mudanças ocorridas nas sociedades contemporâneas. Dentre estas, podemos destacar as notáveis alterações dos perfis epidemiológicos populacionais, caracterizadas por aumento na expectativa de vida, bem como por significativas mudanças nos perfis de morbimortalidade da população mundial.

No Brasil, tal fenômeno ocorreu com grande evidência. Um exemplo emblemático é a expectativa de vida do brasileiro que passou de 53,5 anos em 1970 para 74,08 anos em $2011^{1}$.

Neste cenário brasileiro de mudanças no perfil epidemiológico e de constantes inovações tecnológicas na área da saúde, também chamam atenção melhorias ocorridas no campo da saúde materno-infantil. Observam-se mudanças, principalmente, no perfil da mortalidade infantil, com bruscas diminuições nas últimas décadas, particularmente no seu componente pós-neonatal, de maior significância, quando comparado ao componente neonatal. Em 1980 a taxa de mortalidade infantil no Brasil era de 69,1 óbitos/1.000 nascidos vivos baixando para 16,1 óbitos/1.000 nascidos vivos em 2011, alcançando o quarto objetivo de desenvolvimento do milênio antes do prazo estipulado ${ }^{1}$. Quanto à razão de mortalidade materna, em 1990 eram 143,0/100.000 nascidos vivos caindo para 66,0 óbitos maternos a cada 100.000 nascidos vivos em $2010^{2}$.

Neste sentido, considerando o contexto das políticas públicas de saúde brasileira, o cuidado materno-infantil vem exercendo grande protagonismo nas últimas décadas, com nítidas melhorias dos condicionantes que interferem diretamente na saúde dessa população. Observamos pela história da saúde materno-infantil no Brasil, e da própria história da saúde pública, que foram múltiplas as ações desenvolvidas com o intuito de melhorar as condições de vida e saúde dessa população, mesmo antes da criação do SUS. Porém, com a organização do sistema de saúde brasileiro e as estratégias de mudanças no modelo de atenção à saúde, voltados à prevenção e promoção da saúde, este impacto é sentido com maior intensidade.

Vale a pena citar importantes fatos dessa história. Com tentativas de minimizar a verticalidade dos programas de saúde criados pelo Ministério da Saúde (MS), surge em 1970 o Programa de Saúde Materno-Infantil que apostava na in- tegração das práticas em saúde a fim de buscar a integralidade do cuidado, entendendo que a saúde não depende somente do setor saúde, mas também de ações intersetoriais ${ }^{3}$. Mas as ações continuavam a ser desenvolvidas com foco na saúde da mulher no ciclo gravídico-puerperal e na saúde da criança até dois anos de idade.

Nova tentativa se deu na década de 1980 com o Programa de Assistência Integral à Saúde da Mulher e da Criança, subdividido posteriormente em Programa de Assistência Integral à Saúde da Mulher (PAISM) e Programa de Assistência Integral à Saúde da Criança ${ }^{4}$.

É importante citar que o PAISM foi criado em meio a discussões democráticas entre especialistas na área do cuidado da mulher e criança, bem como por mulheres representantes do movimento feminista do Brasil, até então deixadas à margem das discussões sobre suas próprias necessidades de saúde ${ }^{5}$, e que tal movimento ocorreu em articulação com a proposta de reforma sanitária no Brasil que culminou com a criação do SUS.

Nessa época ficou nítida a preocupação do governo em promover a atenção integral e equânime à população, inclusive relatando a importância da criação de mecanismos de articulação interinstitucional. Mas, de fato, tais ações não se efetivaram de forma a promover o cuidado integral, pois sua implementação passou por diversas dificuldades ${ }^{6}$.

Outros programas também ganharam relevância para a saúde da mulher e criança no Brasil, com a organização do SUS: o Programa de Agentes Comunitários de Saúde (PACS) ${ }^{7}$, que colocava como prioridade melhorias à saúde da criança e o Programa Saúde da Família (PSF), hoje designado por Estratégia Saúde da Família $(\mathrm{ESF})^{8}$, com a tentativa de reorganizar o modelo assistencial, tendo como foco a atenção à família no contexto da discussão acerca da atenção primária à saúde.

Tais estratégias surgem como modelos assistenciais necessários para a consolidação do SUS, visto que previam mudanças no modelo de atenção e na organização dos serviços de saúde, bem como mudanças na forma de financiamento das ações de saúde. Assim, as ações de saúde passam a ter como foco de atuação a família e a coletividade, com ações programáticas e não somente de demanda espontânea ${ }^{7-9}$.

Estudo realizado pelo MS para análise de indicadores frente à cobertura populacional por ESF demonstrou a importância dessa estratégia para a redução da mortalidade infantil. A média 
de declínio anual dessa taxa no estudo citado foi de $3,87 \%$ em todos os estratos de cobertura de ESF ${ }^{9}$. Na área da saúde da mulher os municípios com maior cobertura da ESF vêm apresentando melhores taxas de mães que realizam as consultas pré-natais ${ }^{9}$. A atenção adequada ao pré-natal possibilita o diagnóstico e o tratamento precoce de inúmeras complicações, além de promover educação para comportamentos de risco contribuindo para a redução da mortalidade materna e infantil.

Nesta proposta de reorganização da assistência à saúde através das ESF e mudanças no modelo de atenção, buscando promover práticas de promoção e prevenção de riscos através de ações educativas e empoderamento da população no seu próprio cuidado, inserem-se as práticas de vigilância em saúde. Estas práticas devem fazer parte do trabalho cotidiano das ESF, que em contato direto com os meios de produção, vida e trabalho da população, tem território privilegiado para avançar na mudança do modelo de atenção à saúde. É preciso mudança no processo de trabalho das equipes inserindo a prática da educação permanente com enfoques sobre avaliação de riscos, diagnóstico das necessidades de saúde e o planejamento compartilhado entre as coordenações de atenção primária à saúde e vigilância em saúde. Portanto, acredita-se no potencial que estas equipes têm em promover práticas integradas em saúde ${ }^{10}$.

É possível identificar, através da história das políticas públicas de atenção à saúde materno-infantil no Brasil, diversas estratégias para redução dos coeficientes de mortalidade. Tendo em mente a preocupação em reduzir estes coeficientes ainda elevados no Brasil, o MS publica, em 2011, a Rede Cegonha, através das Portarias 1.459/GM/ $\mathrm{MS}^{11}$ e Portaria 2.351/GM/MS ${ }^{12}$. A política objetiva promover assistência de qualidade, garantir o direito ao planejamento reprodutivo e atenção à gravidez, parto e puerpério, de forma humanizada e qualificada. Prevê, ainda, o direito à criança em nascer, crescer e se desenvolver de forma segura e saudável ${ }^{11,12}$.

Assim, a Rede Cegonha procura operacionalizar as políticas já criadas, mas agora com um diferencial em relação às anteriores, que é a concretização da articulação dos pontos de atenção numa rede de cuidados integrais. Para isso ela propõe construções e reformas em diversos serviços de atenção à saúde, desde a atenção básica, centros de parto normal e maternidades, garantindo atendimento hospitalar de maior complexidade se necessários, incluindo neste percurso os sistemas de apoio e logística também necessários ao cuidado integral. A política tem, portanto, como bases organizacionais, a regionalização e a integralidade, conforme os princípios do SUS ${ }^{11,12}$.

Nesse contexto de integralidade da atenção à saúde como princípio doutrinário do SUS, voltamo-nos à definição deste conceito proposto desde a década de 1990 e ainda pouco efetivado na prática dos serviços de saúde: "um conjunto articulado e contínuo das ações e serviços preventivos e curativos, individuais e coletivos, exigidos para cada caso em todos os níveis de complexidade do sistema"13.

Entre as ações de cunho preventivo, estão as ações de vigilância sanitária (Visa), sendo estas: "[...] um conjunto de ações capaz de eliminar, diminuir ou prevenir riscos à saúde e de intervir nos problemas sanitários decorrentes do meio ambiente, da produção e circulação de bens e da prestação de serviços de interesse da saúde [... $]^{\prime 13}$.

Vê-se que a Visa faz parte do SUS e tem caráter prioritário, visto que a natureza de suas ações é essencialmente de caráter preventivo e de proteção da saúde. Mas, será que as ações de vigilância sanitária estão integradas às demais práticas do SUS com vistas à integralidade do cuidado?

Diversos são os documentos legais que procuram esta integração. A NOB SUS 01/199614 estabeleceu que os municípios assumissem seu pleno exercício de gestores dos serviços de saúde de sua população e propôs a formação de redes regionalizadas e hierarquizadas formadas por pontos de atenção à saúde, proposta enfatizada na NOAS $2001^{15}$. Para a formação das redes foi necessário criar um mecanismo de negociação entre os pontos de atenção para a efetivação da integralidade, a Programação Pactuada e Inte$\operatorname{grada}^{16}$, recentemente substituída pelo Contrato Organizativo da Ação Pública da Saúde ${ }^{17}$.

Para construção da integralidade do cuidado é requisito obrigatório não somente a pactuação da articulação dos pontos de atenção na rede, mas também, da integração das práticas cotidianas, entre elas as ações de vigilância e assistência à saúde, pois compartilhando suas tecnologias haveria maiores possibilidades de alcance de seus objetivos em prol da saúde e qualidade de vida da população ${ }^{18,19}$. Para tanto, torna-se necessário a atuação dos gestores quanto a aplicação deste princípio, promovendo mudanças no modo de agir, redescobrindo e reconstruindo novas práticas em saúde ${ }^{20}$.

No contexto da Rede Cegonha, desde o espaço da micropolítica com a elaboração do desenho municipal, o desenho regional, estadual e 
nacional, onde se levantarão dados referentes à real existência e atuação dos diversos pontos de atenção à saúde materno-infantil, faz-se necessária a participação ativa daVisa na implantação/ implementação da Rede Cegonha. Porém, como nas políticas anteriores e agora na Rede Cegonha, a participação da Visa parece remeter à avaliação da estrutura física dos serviços de saúde que aderirem à política. Mas, apesar de tais documentos não explicitarem esta necessidade de forma direta, eles remetem continuamente à necessidade de prevenção de riscos, promoção da saúde, qualidade do serviço prestado, principal missão da vigilância sanitária. Portanto, reforça-se a importância da sua participação no planejamento e discussão acerca da Rede Cegonha.

As tentativas de inserir a temática da Visa nas demais discussões e planejamentos em saúde são relativamente recentes. O principal documento que explicita esta necessidade de integração, bem como a preocupação do distanciamento da Visa no SUS, data de 2001, durante a $1^{\text {a }}$ Conferência Nacional de Vigilância Sanitária (CNVS). Em parte, acredita-se que este distanciamento se deva à falta de clareza dos profissionais e gestores da saúde sobre a importância das ações de Visa para a saúde coletiva, principalmente com seu papel na promoção e prevenção de riscos à saúde da coletividade, o que facilita a fragmentação das práticas $^{21}$. Posteriormente, em 2007, foi lançado o PDVisa - Plano Diretor de Vigilância Sanitária, que buscou orientar os serviços de Visa no planejamento e desenvolvimentos de ações integradas às demais ações de saúde, na busca pela qualidade de vida e saúde da sociedade ${ }^{22}$.

Enfim, pode-se observar, pelos documentos normativos citados, que as ações em Visa têm como pressuposto inicial trabalhar na promoção da saúde e prevenção de danos à saúde da população, quando avalia os serviços de saúde dos quais a população usufrui, na busca de qualificar seus processos de trabalho, ambiência e assistência. Ao se esgotarem as ações de promoção e prevenção, outras deverão ser produzidas de forma complementar. Além disso, é nítida a preocupação de integrar as ações de Visa com as demais ações de saúde, afinal ela faz parte do sistema público de saúde e tem importante papel para a saúde coletiva.

Assim, o objetivo do estudo foi analisar as estratégias de integração de práticas de Visa e de assistência na Rede Cegonha, bem como o papel dos gestores de Visa e de saúde materno-infantil na busca por esta integração.

\section{Métodos}

Tratou-se de uma pesquisa qualitativa ${ }^{23}$ que utilizou-se das seguintes técnicas: a revisão bibliográfica, a aplicação da entrevista semi-estruturada baseada num roteiro prévio ${ }^{24,25}$ e, por fim, a análise dos resultados utilizando-se da técnica de análise de conteúdo com uso da unidade de registro de tema ${ }^{26,27}$.

Os sujeitos da pesquisa foram gestores de vigilância sanitária (GVisa) e gestores de programa de saúde da mulher (GSM) de quatro municípios pertencentes ao Departamento Regional de Saúde DRS VII, sendo este um dos departamentos pertencentes à divisão administrativa da Secretaria de Estado da Saúde de São Paulo. Entre os municípios escolhidos, estão dois pertencentes à Região de $\mathrm{Saúde}^{28}$ de Campinas e dois da Região de Saúde Oeste, municípios que compõem a Rede Regional de Atenção à Saúde (RRAS) 15, região ampliada na qual se dará a implantação das redes temáticas, entre elas, a Rede Cegonha. Optou-se pela escolha da RRAS 15, visto que esta foi uma das regiões escolhidas pelo Ministério da Saúde para implantação da política no Estado de São Paulo, e pela aprovação desta proposta em reunião do Grupo Bipartite Condutor da Rede Cegonha, conforme Deliberação Comissão Intergestores Bipartite ${ }^{\circ} 34$, de 06 de setembro de 2011. Também se levou em consideração as estruturas físico-funcionais dos municípios em relação à saúde materno-infantil, nos quais já existe projeto em andamento junto ao MS, relativos a recebimento de investimentos para implementação da atual política.

Foram então selecionados os seguintes municípios: Campinas (distritos de saúde norte, noroeste e atores coordenadores das áreas específicas da saúde da mulher e vigilância sanitária), Indaiatuba, Jaguariúna e Santa Bárbara D’Oeste, totalizando 11 entrevistas que foram realizadas pela própria pesquisadora, no período de 07/12/2012 a 14/01/2013.

Os dados foram trabalhados com o uso da técnica de conteúdo temática. As categorias elencadas foram: Integração, Papel do Gestor, Papel da Visa e Espaços Coletivos. Trabalhou-se com as categorias de forma que apresentassem exclusão mútua, homogeneidade em relação à identificação e forma de análise adotada, pertinência do material das categorias em relação ao referencial teórico, objetividade na identificação de temas e categorias e produtividade do material no sentido de fornecer informações. 
A análise da categoria "Integração" permitiu afirmar que as práticas de Visa ainda se encontram isoladas das demais práticas de saúde e que, muitas vezes, são identificadas apenas como práticas fiscalizatórias. Durante as entrevistas alguns GVisa e GSM relataram que a inserção da Visa nas discussões ocorre de forma pontual, e, na maioria, para análise de projetos arquitetônico -estruturais de serviços de saúde.

Apesar disto, percebem-se iniciativas dos gestores na busca pela integração das práticas, pois demostram a importância do trabalho em equipe, promoção de discussões, de inserção nos serviços, inserção nos espaços coletivos, entre outros. Os gestores têm potencial para promover mudanças com intuito de integração das práticas com vistas às melhorias nos serviços oferecidos. Porém, relatam que esta não é uma tarefa fácil, pois envolve relações de poder, empatia e disponibilidade.

Estes achados convergem com outros estudos relacionados ao tema. As práticas de Visa, importantes para a saúde coletiva, vêm historicamente se desarticulando das outras práticas de saúde ${ }^{29-31}$. Em estudo sobre a integração destas práticas junto à assistência à saúde da mulher, na busca pela integralidade do cuidado, também se evidenciou a atuação integrada entre as áreas somente em casos emergenciais, sem programação de atuação conjunta ${ }^{32}$.

Estudo de Christiane Santiago Maia ${ }^{33}$ demonstrou que há consenso de que esta integração não faz parte do trabalho das equipes e que a fragmentação ocorre por motivos como: entendimentos que uma área não depende da outra; por nunca terem pensado na possibilidade do trabalho integrado; e pela falta de apresentação de uma área à outra.

Frente a estes motivos Gastão Wagner de Sousa $\mathrm{Campos}^{34}$ propõe que, para o estabelecimento de vínculos entre as práticas e saberes, é necessário que a Visa chame para a associação, demonstre suas diretrizes, valores e compromissos, porque este posicionamento de 'espera' leva ao isolamento de distintos saberes. Ressalta-se a necessidade de mudanças nos processos de trabalho das vigilâncias sanitárias inserindo, na prática, os conceitos de "(inter) complementaridade e interdependência" na busca por recompor processos de trabalho fragmentados ${ }^{35}$.

Frente às relações de poder existentes e que dificultam o trabalho em saúde, Pinheiro ${ }^{36}$ afirma que as organizações de saúde representam espaços de luta, de exercícios de poderes, nos quais os atores envolvidos constroem suas percepções. Portanto, a ideia de colaboração se torna grande desafio frente aos diferentes graus de domínio. Gastão Wagner de Sousa Campos ${ }^{37}$ propõe mudanças neste sentido, com a incorporação da cogestão nas organizações de saúde. Ou seja, reformas no modo de gerir estas organizações a fim de compartilhar os poderes existentes e promover a autonomia com responsabilidade.

A dificuldade na integração destas práticas pode estar relacionada com desconhecimento dos gestores quanto ao "Papel da Visa", categoria que também apareceu nas entrevistas.

Com a Constituição Federal de 1988 e a implantação do SUS, a lei 8.080, de 1990, define o atual papel da Visa, sendo esta: "um conjunto de ações capaz de eliminar, diminuir, ou prevenir riscos à saúde e de intervir nos problemas sanitários decorrentes do meio ambiente, da produção e circulação de bens e da prestação de serviços de interesse da saúde"13; ou seja, busca desmistificar seu caráter burocrático, normativo e punitivo, para um caráter mais complexo, em conjunto com outras ações de produção e promoção da saúde.

Mas a ideia do seu caráter punitivo, fiscalizatório, ainda era permanente nas práticas sanitárias, o que foi intensamente discutido na $1^{\text {a }}$ CNVS, em 2001. As propostas elaboradas foram em direção às melhorias no processo de comunicação e à visibilidade da Visa junto aos profissionais de saúde e à sociedade ${ }^{21}$.

Quanto às análises das falas dos gestores de Visa, percebeu-se de forma unânime o entendimento de que suas ações não são somente fiscalizatórias e punitivas. Segundo os gestores, mesmo nas práticas fiscalizatórias mais tradicionais, as ações educativas também estão inseridas e isto é uma prática cotidiana nos serviços de Visa. Observou-se, portanto, que as ações de Visa fazem parte da saúde coletiva e que têm grande enfoque na prevenção e monitoramento de riscos à saúde da população. E que seu espectro de ação é realmente grande e complexo, visto que atuam em diversos segmentos produtivos e de saúde.

Em contrapartida, para os GSM entrevistados, o papel da Visa é identificado de forma equivocada. Para a maioria deles, a importância da Visa na Rede Cegonha parece estar ligada ao con- 
trole de doenças na gestação, controle de vacinas, licença sanitária para as construções e reformas de estabelecimentos que atendem gestante, bebê e puérpera.

As falas refletem como a prática da Visa é muitas vezes identificada pelos demais profissionais de saúde, o que, em parte, pode ser sua prática real no cotidiano dos serviços de saúde. Apesar dos gestores de Visa destacarem a importância das ações educativas e do gerenciamento de risco em suas práticas cotidianas, reconhecem que há lacunas na quantidade e na qualidade da formação dos profissionais, o que pode explicar a preponderância do caráter fiscalizatório em detrimento do caráter educativo e pedagógico da Visa.

Historicamente, as relações entre a Visa e demais práticas de saúde, e também entre a Visa e a população, são conturbadas e difíceis. Suas ações estão intrinsecamente relacionadas à produção e consumo de bens e serviços, espaços nos quais se originam grande parte dos problemas de saúde com possibilidade de intervenção e antecipação de um possível dano. Esta prática pode gerar dúvidas às pessoas e profissionais que não enxergam este risco como um problema. Portanto, para que estas relações que envolvem diferentes interesses ocorram de forma mais democrática e participativa, a Visa precisa insistir na sua função de educação sanitária junto à população, trabalhadores, gestores e prestadores de serviços relacionados à saúde, no sentido de reduzir, inclusive os de natureza econômica.

Corrobora-se com a proposta de Ediná Alves Costa $^{38}$ sobre a necessária reorganização das práticas em saúde, inserindo-se nelas as de vigilância sanitária. Há que se adotar uma concepção ampliada de Visa, que privilegie a atuação conjunta dos profissionais de saúde e outros atores importantes no processo de saúde-doença-riscos -agravos, com o compartilhamento de diferentes saberes e tecnologias e a corresponsabilização de todos pela saúde da coletividade.

Gastão Wagner de Sousa Campos ${ }^{34}$ considera que a Visa precisa se ofertar aos demais setores, às demais práticas em saúde, deixando claros seus objetivos em prol da saúde coletiva. Somente assim será possível o estabelecimento de vínculos de confiança importantes para o trabalho conjunto.

$\mathrm{Na}$ análise das duas últimas categorias foi possível observar a importância do gestor na promoção da integração de práticas e da necessidade de espaços coletivos de discussão e planejamento em saúde.

$\mathrm{Na}$ categoria "Papel do Gestor" surgiram ideias sobre o perfil necessário para a promoção da integração das práticas: o "atinar" do gestor, ter postura pró-ativa, inserir-se nas discussões, a permanência da prática integrada, entre outros.

Os gestores também identificam outros atores que seriam de importância no processo de integração: os secretários municipais de saúde, Secretaria Estadual de Saúde, Ministério da Saúde. O que parece transparecer pelas entrevistas é que há um limite entre o que os gestores das áreas específicas podem promover de mudanças e outras questões que escapam da sua governabilidade e de suas iniciativas individuais. Isso traz à tona as relações hierárquicas de poder existentes nas organizações, que em algumas circunstâncias influenciam negativamente, contribuindo para a paralisação no trabalho integrado.

Para Francisco Javier Uribe Rivera ${ }^{39}$, entre as habilidades gerenciais calcadas em uma liderança inovadora e promissora está a capacidade do gestor de articular, agregar e processar continuamente ideias e alternativas de ação e, para isso, o gestor, como líder do processo de mudança e construção de novas estratégias de trabalho em saúde, terá iniciativa, otimismo e persistência.

Mas a ideia de uma única forma de realizar um trabalho, geralmente proposta por um expert, ainda é identificada fortemente quando se vê nas falas dos entrevistados a espera por diretrizes do MS, da Secretaria Estadual de Saúde e até de outros níveis hierárquicos na própria secretaria de saúde municipal. Ou seja, a separação entre expertise os que executam o trabalho, prática taylorista, ainda presente nestas organizações ${ }^{37}$.

Frente às dificuldades existentes por estas dominações, propõe-se a reinvenção dos modos de produção e fluxos de poderes nas organizações de saúde, conforme a lógica de formação de espaços coletivos de cogestão ${ }^{37}$. Os gestores do SUS precisam conhecer as novas propostas de gestão que têm como premissa a reinvenção organizacional no sentido de implantar espaços democráticos de planejamento, negociação e pactuação dos interesses diversos. Esta é uma possibilidade concreta de construção partilhada, democrática e com responsabilização de todos.

Para tanto, há que se pensar em melhorias na formação dos profissionais de saúde, além de promover contínuo processo de educação permanente aos profissionais e gestores do SUS. E que nestes processos educacionais seja inserida a temática Visa. Assim, gestores podem se conhecer e se comprometer com os princípios do SUS e com a saúde coletiva.

Quanto à categoria "Espaços Coletivos", os entrevistados relataram alguns espaços já cons- 
tituídos nos municípios, outros esporádicos, porém com grande valia para melhorias no processo de comunicação e ação. Foram relatadas algumas críticas sobre a falta de espaços sistematizados e organizados com objetos e metas em direção ao planejamento conjunto de ações, por exemplo, da Rede Cegonha.

Quanto aos espaços constituídos, o Colegiado Gestor foi citado por dois gestores de Visa. Este espaço é composto por gestores de diversos setores da Secretaria de Saúde.

Os Colegiados de Gestão são espaços que visam reunir representantes de diversos profissionais das organizações a fim de construir espaços com representação de diversos interesses na busca pela democratização no trabalho e na tentativa de trazer os trabalhadores para a cogestão ${ }^{40}$. Ou seja, são espaços democráticos de negociações e pactuações entre gestores e trabalhadores. Assim, a formação dos colegiados promovem mudanças no paradigma clássico da administração pública. A formação destes espaços vem promovendo mudanças importantes e positivas no modo de se fazer gestão no SUS ${ }^{40}$.

Também foram citadas as reuniões de equipe que ocorrem tanto em distritos de saúde, departamentos de saúde e nas próprias secretarias municipais de saúde. Contam com a presença de diversos profissionais e se discute processos de trabalho, organização dos serviços, condutas profissionais, apresentação da Rede Cegonha etc. Mas vale ressaltar que um entrevistado GSM relatou que a reunião de equipe constituída no seu município, muitas vezes, engloba somente profissionais de enfermagem.

As reuniões de equipe são espaços importantes para discussões de casos, redefinições de práticas, de educação permanente, de planejamento e avaliação. É também um espaço de cogestão, onde as decisões são tomadas em conjunto, facilitando assim, a resolução de problemas comuns ${ }^{41}$.

Também foi relatada pelos gestores das duas áreas do estudo, a existência de Comitês de Investigação de Óbitos Maternos e Infantis, mas sem participação ativa da Visa. Contudo, dois GVisa participam deste comitê por trabalharem na lógica da vigilância em saúde. Percebe-se que este espaço é muito importante para a discussão e planejamento de ações, mudanças nos processos de trabalho, na organização dos serviços de saúde, com vistas a melhorias na saúde da materno -infantil. Acredita-se na urgente necessidade de inserir a Visa nestes espaços.
Outro espaço constituído foi criado a partir da necessidade real das equipes de Visa e dos serviços por elas fiscalizados; são as reuniões mensais entre equipe de Visa e maternidade/hospital. Também há relatos de alguns GSM sobre estas discussões junto aos serviços, porém tais práticas entre Visa, programa saúde da mulher e serviços assistenciais não se dão de forma integrada, mas paralela.

Em relação à existência de espaços temáticos, observou-se a constituição do Grupo Condutor Regional da Rede Cegonha e o Grupo Condutor Municipal da Rede Cegonha, este último formalizado apenas em um município. Porém tal espaço não contempla a participação ativa da Visa, mas apenas quando há necessidade, como relatam os entrevistados GSM e GVisa deste município.

Todos os espaços citados têm sua importância na produção de saúde no SUS. Mas vale ressaltar algumas questões frente às necessidades de melhorias destes espaços. Com a política de humanização do SUS, novas práticas de gestão vêm sendo adotadas em diversas organizações de saúde, com intuito de mudar o modelo tradicional da administração clássica que produz um trabalho alienado ${ }^{42}$. A proposta é de promover espaços coletivos (espaço-tempo para o exercício da cogestão) de produção de sujeitos ativos no processo de cuidar e gerir os serviços, ou seja, considerando a função primária da organização (de produzir saúde), mas também a secundária, porém não menos importante, de produção de sujeitos $^{42}$.

Estes espaços são ocupados por sujeitos com distintos desejos, interesses e necessidades e, portanto, são bastante complexos nas organizações de saúde. A inclusão de novos sujeitos nos espaços de gestão traria como pontos positivos a ampliação da implicação e a corresponsabilização com o cuidado, uma vez que as definições das práticas adotadas seriam negociadas e pactuadas. A produção e implicação partilhada também aumentaria a produção de saúde, uma vez que a vontade de fazer estaria ampliada. Assim, faz-se uma crítica em relação a alguns espaços como reuniões somente com profissionais de enfermagem ou grupo condutor da Rede Cegonha para consolidar práticas médicas. Entende-se que o processo de cuidar é bem mais amplo e a participação de demais integrantes de equipes de saúde de diversas organizações pode favorecer a produção de sujeitos implicados com a saúde coletiva. 


\section{Conclusão}

A partir dos objetivos desta pesquisa, os resultados apresentados convergem com a pequena bibliografia encontrada que também buscou desvendar estas práticas integradas, qual seja, o histórico isolamento das práticas de Visa frente às demais práticas de saúde. Ainda demostraram que parte deste isolamento se dá pelo desconhecimento do papel da Visa na promoção da saúde e prevenção de riscos e danos advindos do processo produtivo e de intervenções em saúde, principalmente por parte dos gestores da área da saúde da mulher, ainda com um olhar sobre a Visa como prática fiscalizatória no quesito aprovação de projetos arquitetônicos. Apesar disto, a maioria reconhece a necessidade de se integrar às práticas de Visa e assistência na Rede Cegonha e propuseram mecanismos para melhorias nesta integração.

Concorda-se com $\operatorname{Costa}^{38}$ que, para ocorrer uma mudança no processo de trabalho em saúde, que vise a uma nova concepção da Visa, inserida e articulada com as demais práticas de saúde, há que se promover o envolvimento dos profissionais de Visa com os demais profissionais de saúde. Há também consonância com o encontrado por Luchese ${ }^{43}$, quando afirma que a natureza do trabalho em Visa exige ações interdisciplinares e interinstitucionais concretizadas em canais de participação constituídos que representam um poderoso mecanismo de articulação de poderes em prol de efetivação de ações e democratização da gestão.

Estes canais de participação se darão na construção de espaços coletivos de cogestão, como proposto por $\mathrm{Campos}^{37}$. Serão espaços de produção de subjetividade passíveis de transformações, de permanente coprodução, negociação e renegociação de contratos e compromissos.

Portanto, acredita-se que por a Visa ainda ser vista por muitos profissionais de saúde como práticas isoladas da saúde coletiva (importantes, mas isoladas), torna-se necessário que os profissionais desta área busquem meios de mudar esta visão. Um destes meios é sua inserção ativa em espaços coletivos de gestão.

Frente aos resultados encontrados, concluise que, apesar da RRAS 15 ser reconhecida como uma das regiões de saúde com maior avanço na implantação/implementação da Rede Cegonha, já que foi escolhida pelo Ministério da Saúde e pela Secretaria de Estado da Saúde de São Paulo como precursora para o desenvolvimento da política em 2011, práticas de Visa e assistência continuam fragmentadas, com integrações pontuais. Mesmo com o esforço dos gestores das áreas e da existência de alguns espaços e criação de outros para discussão e planejamento das ações a serem desenvolvidas na Rede Cegonha, a desarticulação destas práticas ainda persiste no cotidiano dos serviços de saúde.

\section{Colaboradores}

RZS Fernandes participou de todas as etapas da elaboração do artigo; MFG Vilela participou da organização, redação e revisão final do artigo. 


\section{Referências}

1. Instituto Brasileiro de Geografia e Estatística (IBGE). Tábua completa de mortalidade para o Brasil - 2011. Breve análise da mortalidade no período 2000-2011. Rio de Janeiro: IBGE; 2012.

2. Brasil. Ministério da Saúde (MS). Sistema de Informações sobre mortalidade [internet]. Painel de Monitoramento da Mortalidade Materna. [acessado 2013 jul 12]. Disponível em: http://svs.aids.gov.br/dashboard/ mortalidade/materna.show.mtw

3. Brasil. Ministério da Saúde (MS). V Conferência Nacional de Saúde [anais]. Brasília: MS; 1975.

4. Brasil. Ministério da Saúde (MS). Gestões e gestores de políticas públicas de atenção à saúde da criança: 70 anos de história. Brasília: MS; 2011.

5. Costa EA. Vigilância Sanitária: proteção e defesa da saúde. São Paulo: Hucitec, Sobravime; 1999.

6. Serruya JS, Lago TG, Cecatti JG. Avaliação preliminar do Programa de Humanização no Pré-natal e Nascimento no Brasil. Rev Bras Ginecol Obstet 2004; 26(7):517-525.

7. Brasil. Ministério da Saúde (MS). Programa Agentes Comunitários de Saúde (PACS). Brasília: MS; 2001.

8. Brasil. Ministério da Saúde (MS). Guia Prático do Programa Saúde da Família. Brasília: MS; 2001.

9. Brasil. Ministério da Saúde (MS). Saúde da Família no Brasil: uma análise de indicadores selecionados, 19982005/2006. Brasília: MS; 2008.

10. Vilasbôas ALQ, Teixeira CF. Saúde da família e vigilância em saúde: em busca da integração das práticas. Brasília: MS; 2007. (Rev. Brasileira Saúde da Família)

11. Brasil. Ministério da Saúde (MS). Portaria no 1.459/ GM/MS, de 24 de junho de 2011, que institui, no âmbito do Sistema Único de Saúde (SUS), a Rede Cegonha. Diário Oficial da União 2011; 25 jun.

12. Brasil. Ministério da Saúde (MS). Portaria no 2.351/ GM/MSde 5 de outubro de 2011. Altera a Portaria ${ }^{\circ}$ 1.459/GM/MS, de 24 de junho de 2011, que institui, no âmbito do Sistema Único de Saúde (SUS), a Rede Cegonha. Diário Oficial da União 2011; 27 jul.

13. Brasil. Lei 8.080, de 19 de setembro de 1990. Dispõe sobre as condições para a promoção, proteção e recuperação da saúde, a organização e funcionamento dos serviços correspondentes e dá outras providências. Diário Oficial da União 1990; 20 set.

14. Brasil. Ministério da Saúde (MS). Portaria n 545 GM/ MS, de 20 de maio de 1993. Norma Operacional Básica NOB-SUS n ${ }^{\circ} 1 / 96$. Diário Oficial da União 1996; 6 nov.

15. Brasil. Ministério da Saúde (MS). Portaria no 95 GM/ MS, de 26 de janeiro de 2001. Norma Operacional da Assistência à Saúde / NOAS-SUS 01/2001. Diário Oficial da União 2001; 29 jan.

16. Brasil. Ministério da Saúde (MS). Portaria $n^{\circ} 1.020$ GM/MS, de 31 de maio de 2002. Define a Programação Pactuada e Integrada. Diário Oficial da União 2002; 6 jun.

17. Brasil. Ministério da Saúde (MS). Decreto 7.508, de 28 de junho de 2011. Regulamenta a Lei $n^{\circ} 8.080$, de 19 de setembro e 1990, para dispor sobre a organização do Sistema Único de Saúde - SUS, o planejamento da saúde, a assistência à saúde e a articulação interfederativa, e dá outras providências. Diário Oficial da União 2011; 29 jun.
18. Brasil. Ministério da Saúde (MS). Portaria no 3.252/ GM/MS, de 22 de dezembro de 2009. Aprova as diretrizes para execução e financiamento das ações de Vigilância em Saúde pela União, Estados, Distrito Federal e Municípios e dá outras providências. Diário Oficial da União 2009; 23 dez.

19. Brasil. Ministério da Saúde (MS). Portaria no 4.279/ GM/MS, de 30 de dezembro de 2010. Estabelece as diretrizes para a organização da Rede de Atenção à Saúde no âmbito do Sistema Único de Saúde (SUS). Diário Oficial da União 2010; 31 dez.

20. O’Dwyer G, Reis DC, Silva LL. Integralidade, uma diretriz do SUS para a vigilância sanitária. Cien Saude Colet 2010; 15(Supl. 3):3351-3360.

21. Brasil. Ministério da Saúde (MS). $1^{\text {a }}$ Conferência Nacional de Vigilância Sanitária: Relatório Final. Brasília: Agência Nacional de Vigilância Sanitária; 2001.

22. Brasil. Ministério da Saúde (MS). Portaria no 1.052, de 8 de maio de 2007. Aprova e divulga o Plano Diretor de Vigilância Sanitária. Diário Oficial da União 2007; 9 mai.

23. Bosi MLM. Pesquisa Qualitativa em Saúde Coletiva: panorama e desafios. Cien Saude Colet 2012; 7(3):575586.

24. Triviños AN. Introdução à pesquisa em ciências sociais: a pesquisa qualitativa em educação. São Paulo: Atlas; 1987.

25. Neto OC. O trabalho de campo como descoberta e criação. In: Deslandes SF, Neto OC, Gomes R,Minayo MC, organizadores. Pesquisa Social: teoria, método e criatividade. Rio de Janeiro: Editora Vozes; 1994. p.6780.

26. Bardin L. L'Analyse de contenu. Paris: Presses Universitaires de France; 1977.

27. Minayo MC. O desafio do conhecimento. Pesquisa qualitativa em saúde. Rio de Janeiro: Abrasco; 2004.

28. São Paulo. Secretaria de Estado da Saúde (SES SP). Pacto pela saúde - Plano Diretor de Regionalização - PDR do Estado de São Paulo. São Paulo: SES SP; 2008. 29.

29. Souza AMAF. Vigilância sanitária na saúde pública brasileira e sua aproximação com o caso mexicano: proteger, vigiar e regular [tese]. São Paulo: Universidade de São Paulo; 2007.

30. Costa EA. Vigilância Sanitária: proteção e defesa da saúde [tese]. São Paulo: Universidade de São Paulo; 1998.

31. Maia CS. Inserção da vigilância sanitária na política de saúde brasileira [tese]. Brasília: Universidade de Brasília; 2012.

32. Maia C, Guilhem D, Lucchese G. Integração entre vigilância sanitária e assistência à saúde da mulher: um estudo sobre a integralidade no SUS. Cad Saude Publica 2010; 26(4):682-692.

33. Maia CS. Vigilância Sanitária e saúde da mulher: um estudo sobre a integralidade no SUS [dissertação]. Brasília: Universidade de Brasília; 2007.

34. Campos GWS. Vigilância Sanitária: responsabilidade pública na proteção e promoção da saúde. In:1 a Conferência Nacional de Vigilância Sanitária; 2001; Brasília. p. 9-17. 
35. Souza GS, Costa EA. Considerações teóricas e conceituais a cerca do trabalho em vigilância sanitária, campo específico do trabalho em saúde. Cien Saude Colet 2010; 15(Supl. 3):3329-3340.

36. Pinheiro R. As práticas do cotidiano na relação oferta e demanda dos serviços de saúde: um campo de estudo e construção da integralidade. In: Pinheiro R, Mattos RA, organizadores. Os sentidos da integralidade na atenção e no cuidado à saúde. Rio de Janeiro: Abrasco; 2006. p. 65-112.

37. Campos GWS. Um método para análise e co-gestão de coletivos. São Paulo: Hucitec; 2000.

38. Costa EA. Vigilância Sanitária: desvendando o enigma. Salvador: EDUFBA; 2008.

39. Rivera FJU. Negociação Gerencial e Liderança. In: De Seta MH, Pepe VLE, Oliveira G, organizadores. Gestão e vigilância sanitária: modos atuais do pensar e fazer. Rio de Janeiro: Fiocruz; 2006. p. 71-87.

40. Cecílio LCO. Colegiado de gestão em serviços de saúde: um estudo empírico. Cad Saude Publica 2010; 26(3):557-566.

41. Brasil. Gestão participativa e cogestão. Brasília: Ministério da saúde (MS); 2009.

42. Cunha GT, Gastão WS. Método Paidéia para co-gestão de coletivos organizados para o trabalho. ORG \& DEMO 2010; 11(1):31-46.

43. Luchese G. A vigilância sanitária no sistema único de saúde. In: De Seta MH, Pepe VLE, Oliveira G, organizadores. Gestão e vigilância sanitária: modos atuais do pensar e fazer. Rio de Janeiro: Fiocruz; 2006. p. 37-47.

Artigo apresentado em 31/10/2013

Aprovado em 10/04/2014

Versão final apresentada em 14/04/2014 